\title{
A fotografia contemporânea tem uma história? ${ }^{1}$
}

\section{Does contemporary photography have a history?}

Michel Poivert

Tradução: Andrea Eichenberger 


\section{Resumo}

No presente artigo, Michel Poivert retoma temáticas tratadas no livro La photographie contemporaine, publicado inicialmente em 2002 e reeditado e ampliado em 2010, a fim de atualizar suas observações sobre este fenômeno que passa por constantes transformações.

\section{Abstract}

In this article, Michel Poivert sets out some issues addressed in the book Photographie contemporaine, first published in 2012 and reissued and expanded in 2010. He updates his observations on contemporary photography, this phenomenon that undergoes constants changes.

ISSN: 2175-2346 
Fazer esta pergunta implica dizer que a expressão "fotografia contemporânea" cobre uma realidade suficientemente identificável para ser constituída em objeto de história. Se essa realidade pode, sem dificuldade, ser manifestada pela enumeração de um corpo, pela sucessão de eventos marcantes, pelo volume de comentários e de análises, ou ainda pela percepção de alguns eixos e problemáticas fortes sobre um período de mais ou menos uma geração - se então a "fotografia contemporânea" não se constitui em uma ilusão historiográfica, não deixa de ser verdade que essa realidade é de uma grande diversidade, e que pela falta de distanciamento, sua descrição pode tornar-se uma aventura. A fotografia contemporânea "é" uma história, sem contestação, mas ela "tem" uma história? E, se sim, de que história se trata?

Eu pude escrever em La photographie contemporaine (Flammarion, 2002) ${ }^{3}$, e mantenho essa ideia, que a fotografia contemporânea se define como um momento histórico onde a fotografia é contemporânea da arte, num período onde esta é nomeada, em grande parte, "arte contemporânea". Como se o adjetivo, aqui e ali, garantisse uma atualidade (lembremos que a arte "sendo feita" foi anteriormente chamada de art vivant, arte de hoje, arte atual, significando, em todos os casos, seu presente histórico). Em outras épocas, a fotografia conheceu sua atualidade em uma relação de contemporaneidade com a informação, ou ainda com a ciência ou a indústria. Constata-se que, depois dos anos 1970, a atualidade mais evidente da fotografia se constituiu em sua relação com a arte contemporânea. Isto, no entanto, não pode ser pensado sem dificuldades, pois, de fato, a fotografia não se constituiu como corrente artística identificável de forma autônoma. Lembremos que a fotografia contemporânea não conheceu um evento inaugural, um manifesto ou qualquer outro marco de origem. Os comentaristas muito falaram de "entrada na arte", de autonomia ou de outros processos, mas falta descrevê-los e analisá-los de um ponto de vista histórico. Por outro lado, a dificuldade de falar sobre a vinculação da fotografia à arte contemporânea - pois se trata disso -, não testemunha de uma constante atualidade da fotografia contemporânea? Utilizou-se ferramentas sociológicas, em falando do "campo" da fotografia contemporânea, mas este campo, para existir se "temporalizou", houve então uma relação ao tempo histórico: uma historicidade nascente da fotografia contemporânea.

O que é um pouco mais evidente é que hoje as coisas estão visivelmente engajadas a uma "saída" da arte contemporânea. Para quem observa os laboratórios que formam as feiras de arte contemporânea, assim como as mais diversas e variadas bienais: há vários anos a fotografia quase não se faz mais presente (mesmo se a "imagem", notadamente sob a forma de projeção ou de filme, está fortemente presente). De todo modo, mesmo se ainda encontramos dificuldades para identificar uma origem, estamos diante de sintomas patentes do fim da fotografia contemporânea compreendida como momento de uma história comum à arte e a à fotografia. O que não impede que alguns fenômenos sejam resultantes disso e que uma certa fotografia continue existindo, que a arte na sua diversidade de práticas continue mobilizando a imagem do tipo fotográfi-

\footnotetext{
${ }^{1}$ Artigo traduzido do francês, publicado inicialmente no livro "Photographie contemporaine \& art contemporain". Sous la direction de François Soulages \& Marc Tamisier. Ed. Klincksieck, 2012.

2 Os grifos ao longo do texto respeitam a versão original fornecida pelo autor.
}

3 Livro publicado inicialmente em 2002, reeditado e ampliado em 2010. Flammarion, Paris. 
ca... mas uma coisa parece cada vez mais certa: não é mais numa história comum entre fotografia e arte contemporânea que ambas se atualizam. Último sobressalto talvez: o sucesso recente de certos fotojornalistas no cenário artístico contemporâneo. Parece que o destino lhes confiou a trágica missão de realizar os últimos tableaux. Esta é a razão pela qual eu inverteria voluntariamente minha fala inicial, afirmando que a fotografia contemporânea deve, hoje, ser pensada historicamente para continuar existindo e que, deste modo, seja reconhecido o que ocorreu ao mesmo tempo com a arte e a fotografia em um período de mais ou menos vinte e cinco anos. É historicizando a fotografia contemporânea que ela será poupada do esquecimento, e este trabalho será feito ao se pensar em uma história comum à arte e à fotografia.

Essa história comum parece ter conhecido uma reviravolta decisiva no início dos anos 1980, mas, para qualificá-la, é necessário observar qual foi até então - e desde as origens da fotografia - o modo de existência da fotografia na historicidade da arte. Podemos dizer que a fotografia sempre foi um contra-modelo para a arte: no que ela perpetua uma estética mimética de exatidão enquanto que a arte moderna a condena; no que ela simboliza a trivialidade da padronização pela sua reprodutibilidade quando a arte moderna defende a singularidade contra a escola; ela assegura com uma real permanência até o inicio do século XX uma espécie de anti-arte moderna. A grande modificação percebida desde os anos 1910 com personalidades dadaístas como Picabia e Duchamp é a abertura deste contra-modelo a uma dimensão estética vertiginosa. Enquanto que a morte da arte é defendida, a fotografia troca seu estatuto negativo de contra-modelo para encarnar a força niilista de uma arte em negativo: sem estilo, sem emoção, sem esforço, sem original etc. A fotografia incarna o cadáver que a arte ambiciona ser para melhor renascer. "A ideia de fotografia" (expressão de François Brunet) conhece então uma inversão radical: continuando a ser ela mesma, num momento em que se sustenta uma arte sem aura, a fotografia passa por uma revolução que a transforma nesta própria arte sem aura.

Esse prestígio niilista ocorreu em paralelo a uma história internalista da fotografia, internalista e contraditória pois a partir dos anos 1930, e em seguida a um pictorialismo anglo-saxônico, a fotografia artística ganha espaço e obtém uma legitimação progressiva. Mas essa legitimação não explica em nada, me parece, a história comum à arte e à fotografia. Ela é exterior a essa história, como seu reflexo invertido - pois até os anos 1970, notadamente com o impacto da arte conceitual, a fotografia conserva uma estética potente, inversamente proporcional à sua qualificação artística. Isto pode parecer difícil a ser pensado, mas é exatamente disso que se trata: uma tensão progressiva entre o estatuto artístico e a potência estética. Tanto que, para a arte, a fotografia é seu Outro, ela lhe é útil nesta própria alteridade (lembremos a formula de Walker Evans: "a arte não é um documento, mas pode adotar o estilo" - Katz, 1971).

Poderíamos resumir a questão dizendo que até o limiar dos anos 1980, a fotografia representa para a arte uma "imagem", algo então de "cultural". Nesta expressão podemos ler duas coisas: primeiro que a cultura não é arte (Hannah Arendt não definia a arte como uma "rebelião contra a cultura"?), e sobretudo que sob a cobertura da cultura todas as imagens fotográficas (da mais simples à mais sofisticada, da vinheta do dicionário à propaganda mais virtuosa) têm valor e mérito para entrar na grande eco- 
nomia iconográfica do desvio, da reutilização e de todo uso artístico. O que a arte fez da fotografia durante muito tempo, e com genialidade, consistiu em arruinar seu valor utilitário, reciclando-a e tornando-a uma proposta estética. Mas a arte soube preservar uma relíquia desse valor utilitário, por ter indicado em suas próprias práticas que a fotografia carrega sua parte de trivialidade (recorte de jornais por exemplo). A aura niilista da fotografia vai contudo ceder espaço a algo completamente diferente no final dos anos 1970, e é dessa mudança que sairá a fotografia contemporânea.

O que acontece na história comum à arte e à fotografia que faz com que, durante um breve período, esta última pare de incarnar uma anti-arte, o que era - do meu ponto de vista -, talvez a dimensão histórica capital deste meio? Podemos levantar diversas hipóteses para abordar essa questão. A fotografia torna-se subitamente arte (pela arte)? Mais uma vez: independentemente de uma tradição "fine arts" da fotografia. É preciso, para examinar uma tal hipótese, lembrar que uma ruptura - talvez a mais importante - na arte contemporânea da virada dos anos 1970 aos anos 1980 é o grande retorno da pintura. E mais precisamente ainda, o grande retorno de uma pintura figurativa então catalogada de Figuração Livre na França, de Neo-Expressionismo ou Neo-Fauvismo na Alemanha, de Transvanguarda na Itália ou ainda Bad Painting nos Estados Unidos. O que acontece com a arte, depois do sucesso da arte conceitual, é essa revolução no sentido de um retorno do que lhe era comum, da matéria pictórica, do tableau, da figura.

Este dado foi questionado, até o presente, em vista do sucesso da fotografia no campo da arte contemporânea? Talvez não o suficiente. Paremos então por alguns instantes com uma questão provocativa: a fotografia contemporânea não participa então de um retorno da arte retiniana, seria ela um avatar do retorno da figuração? Se examinarmos essa conjunção que me parece capital, podemos formular uma segunda questão, mais justa: a fotografia não participa do retorno de um interesse pelo visível, sem no entanto trair a imaterialidade da arte conceitual? A iconofobia da arte conceitual (retomando a análise de John Roberts) sempre esteve em contradição com o gosto pelas imagens documentais desta corrente, e a fotografia permitia justamente não valorizar a representação, servindo assim à retórica conceitualista. Produzir imagens sem entrar no valor da representação. A fotografia contemporânea, e podemos pensar no primeiro Jean Marc Bustamante, alia admiravelmente o gesto artístico do formato designado como tableau e o prosaísmo da iconografia próxima da tradição conceitual. A fotografia permite incarnar o estrito necessário da arte desmaterializada, dando-lhe não uma carne, mas um envelope. Mas a imagem, tendo por natureza uma relação nativa com a ilusão, deverá esvaziar-se de todo conteúdo para valorizar somente a força de sua aparência, uma pura operação da visão. A fotografia não foi então capaz de responder à nova atualidade da pintura? Em certos aspectos, a fotografia contemporânea passaria para "concretizar" o conceitualismo e assegurar sua sobrevivência frente à atualidade de um retorno da pintura, da matéria e do conteúdo opondo-lhe o rigor da transparência compreendida como garantia da primazia das ideias.

A diversidade de produções da fotografia contemporânea certamente não permite propor uma leitura unilateral, mesmo se me parece possível sustentar a ideia de que uma parte importante da fotografia contemporânea manteve viva a primazia de 
uma arte de ideias no final do século XX, ao lado de práticas de instalação e de atitude. Encontramos um outro exemplo com, o que eu chamaria, sucesso das imagens performatizadas: numerosos artistas se transformaram em performers da imagem - e isto numa tradição que não é obrigatoriamente a do happening, mas de autênticos artistas da imagem performatizada, como William Wegman ou ainda Bruce Nauman. No caso de um Paul Pouvreau, ou de um Édouard Levé, ou ainda de um Philippe Ramette, temos hoje, na França, uma fotografia onde a mise en scène não é simplesmente uma construção em um quadro específico, mas a materialização, após um desenho preparatório, de uma ação pela imagem - o que era normalmente o caso de performers históricos para os quais a imagem se constituía em um lugar de materialização (no caso de Gina Pane ou ainda Rudolf Schwarzkogler). Então sim, mais uma vez, em um certo sentido, uma parte da fotografia contemporânea se apresenta como uma arte de ideias pela imagem, no tempo do retorno à pintura.

Mas não se trata de compreender a fotografia contemporânea em seu conjunto sob este único ângulo, mesmo se ele parece esboçar uma história comum. O que é certo, no entanto, é que a fotografia compreendida como materialização da arte conceitual acumula um capital intelectual, um caráter especulativo, ausente na tradição "fine arts" da fotografia. E é como se toda a história da fotografia como anti-arte viesse se precipitar (no sentido químico do termo) no final do século XX para impor o somatório de ideias que estiveram no centro de sua instrumentalização pela arte das vanguardas, para se transformar em uma espécie de arte nova, plena de seu passado niilista. A fotografia se tornava uma arte séria: não nos explicaram, nos anos 1970, que Duchamp se deixava compreender por meio da fotografia? Esta se tornava a chave para a leitura da arte do século XX.

O que se destaca em meio a tudo isso é um regime específico que marca os inícios da fotografia contemporânea, pois, repito, o grande tópico da arte contemporânea no limiar dos anos 1980 é duplo e paradoxal: retorno da pintura versus entrada da fotografia. Porém, esta entrada não é uma irrupção, um advento, mas uma espécie de inversão da própria história da arte. É através de uma tipologia, ao mesmo tempo de práticas e de regimes de historicidade, que destacarei os principais eixos de uma possível história da fotografia contemporânea. Pois se "tudo" parte de uma certa concepção que a arte tinha da fotografia no século XX, é preciso considerar que (quase) todos os tipos de fotografia iam, muito em breve, se posicionar em relação à arte, e é nesses numerosos reposicionamentos - os quais compreendemos como o fruto de uma expectativa da arte como fotografia - que uma história comum se desenha na sua globalidade.

A primeira delas, em termos de cronologia mas também de manifestação de suas intenções, é provavelmente uma fotografia que se reveste do caráter da experimentação plástica. Desde o início dos anos 1980 - e talvez hoje de uma maneira reativada pelas potencialidades dos novos dispositivos digitais - os artistas trabalharam por uma abertura do dispositivo fotográfico, através de mil desregulações, a fim de obter resultados frequentemente inéditos. Trabalhos sobre a própria matéria da imagem, metamorfoses dos espaços, renovação das práticas de montagem atingindo os limites do heteróclito. Essa fotografia, que qualifico voluntariamente pelo termo genérico "experimental", marcou por um tempo o caráter inovador da fotografia contemporânea. 
Mas, paradoxalmente, essa fotografia experimental talvez seja a mais próxima de repetir uma tradição herdada da grande figura mítica das vanguardas. Das práticas ditas pobres às sofisticações extremas dos processos digitais, encontramos nessa fotografia experimental a vontade de romper com as práticas normativas e instituir um jogo com o visível como propulsor da criatividade. A serviço de uma poética, por vezes crítica, por vezes onírica, a fotografia experimental desafia o uso da imagem, sonha com uma relação com o real construída sobre a subjetividade, arruína toda uma tradição de uma imagem definida pela sua continuidade descritiva. Os órgãos da poética experimental ressoam ainda, remexem na nossa história retomando os procedimentos originais do registro, se reconectam com a impressão luminosa nativa para projetá-la no século que está por vir, com o acento messiânico que tinham os fotogramas da "Idade da luz" de Man Ray. Uma repetição, então, essa fotografia experimental, repetição de nossas obsessões em desafiar o visível até o ponto, por vezes, de transformar a técnica em fetiche. Mas nada de pejorativo em meu espírito: se a fotografia experimental instala a potência da tradição vanguardista na fotografia contemporânea, é provavelmente porque numerosos são os artistas que também trabalham a fotografia em outro sentido, transformando-a no coveiro da ideologia das rupturas históricas.

Eu penso, é claro, em um segundo tipo de produção da fotografia contemporânea, tipo que talvez incarne, aos olhos de todos, uma fotografia sinônimo de arte contemporânea. Uma fotografia cuja identidade histórica está marcada pela adoção dos princípios da arte sob um modo que não é o das rupturas vanguardistas mas da afirmação de valores da arte e de sua autonomia. Qualifico historicamente essa fotografia, cuja obra de Jeff Wall é altamente emblemática, de revisão do modernismo. Ela se dá geralmente sob a forma de uma imagem construída, e no caso significativo de Wall, como a afirmação de uma tradição da arte. Não sob a forma elementar de uma citação (ou seja, em uma versão pós-modernista), mas como uma representação em toda sua autoridade de discurso auto-referencial. Uma certa ideologia da arte entra em cena nessa parte da fotografia contemporânea, no sentido em que a fotografia como meio específico não vem aqui atuar com a desordem da arte estabelecida, mas ao contrário, vem confirmar a ordem histórica. É certo que toda imagem fotográfica construída não corresponde a este princípio, a mise en scène pode se revestir, em sua própria teatralidade, de formas diversas, mas o que significava o sucesso da fórmula do tableau (e do fetichismo intelectual que a sustentou) permitiu assegurar à fotografia contemporânea um crédito modernista sem igual. Estamos longe de uma fotografia experimental que indexa seu valor sobre o enigma do visível e sobre a fecundidade das práticas inéditas que tentam reproduzir uma revolução. Mas estamos no centro dos valores acordados à obra de arte, ou seja, de uma superioridade da representação sobre todo determinismo histórico.

Para contradizer essa fotografia de ambições a-históricas, já nos inícios dos anos 1990, vemos aparecer uma proposição que vai varrer literalmente os antigos debates e se incarnar em muitas práticas, o documento. A nova atualidade da questão documental se dá em um contexto de repolitização geral do campo artístico. É o que testemunham as bienais, os escritos e os debates: depois dos anos 1980 intensamente apolíticos, o peso obtido pela comunicação no campo das imagens consegue semear 
a confusão chegando a um relativismo total dos valores que todo o pós-modernismo valida. Dos simulacros às paródias, a comunicação e a arte parecem confundir-se. Diante da necessidade de distinguir uma foto de publicidade de uma obra de arte, a fotografia documental vai impor uma alternativa fazendo ressurgir fundamentos estilísticos e iconográficos: mostrar simplesmente, e se colocar a serviço de um assunto. $O$ documental implica no conhecimento aprofundado de seu assunto, e eu diria que sua "feitura" no sentido estilístico, deve em permanência tomar uma certa distância e neutralidade para revelar problemáticas normalmente políticas. Esse trabalho de revelação se opõe radicalmente ao pós-modernismo e à sua sofisticação semiótica. Trata-se, com o documento, de se situar um pouco fora da arte e um pouco fora da informação, em um espaço mais neutro onde a historicidade está marcada pela figura da utopia. Então, não é "o mundo como ele é" nem o testemunho nu, é a reflexão aprofundada sobre o estatuto da imagem e do sujeito que atuam, e uma de suas figuras centrais é Allan Sekula. Todavia, esses trabalhos documentais, mesmo se buscam uma certa ética, não têm todos uma vocação sociopolítica, na tradição do reformismo social de Lewis Hine; certas obras como as de Jean-Luc Moulène são claramente mais libertárias, o que não impede essa retórica documental afirmada. O sucesso do documental vem do fato de ele ter reativado a conexão entre a imagem e o mundo. O trabalho essencial dessa fotografia contemporânea de tipo documental se mede notadamente entre os artistas que se questionaram sobre a memória. De Sophie Ristelhueber a Arno Gisinger, a imagem na sua potência descritiva se torna um lugar de produção de formas-vestígios que parecem conectar fisicamente a realidade e a história.

A quarta vertente se desenhou por volta do final dos anos 1990 e não é indiferente a essa revalorização do documental do qual ela aparece como um avatar: uma confrontação da fotografia de reportagem à arte e às suas instituições. Promovida por uma estratégia dos autores e por uma busca de legitimidade artística, a reportagem precisou se inscrever em um diálogo com a arte nesse fim de século XX. Mas uma cultura própria à fotografia, que eu nomearia "cultura de agência", impediu rapidamente a eclosão de uma história comum a arte e a esta prática, mesmo se certas figuras como Raymond Depardon são notavelmente uma exceção (mas, para dizer a verdade, este foi, desde o início, alimentado por uma vontade de ruptura com a tradição da reportagem - lembremos que Notas em 1979 é publicado por um editor de poesia). Mas foi onde não se esperava a cultura fotográfica da informação, ou seja, em sua forma de produção a mais profissional e a mais estranha à arte, no fotojornalismo puro, que uma ponte com a arte contemporânea se edificou de maneira singular. O que vivemos recentemente, e que chamo de "estetização do fotojornalismo", foi particularmente revelador do apetite de uma época pela tentativa de articular arte e mídia sob a bandeira da história, tentado ver restaurada uma série de imagens históricas, sendo o trabalho de Luc Delahaye emblemático.

A fotografia contemporânea não é então, repitamos para terminar, uma "categoria" da arte contemporânea, assim como tampouco se limita a uma única produção casando com os princípios da produção plástica contemporânea qualquer que seja sua diversidade. A pluralidade da fotografia contemporânea faz dela um fenômeno, não uma corrente ou um movimento, mas um momento onde a flutuação de valores da fo- 
tografia se encontra na sua amplitude máxima e sob vertentes diversas. A que destino histórico está reservada a fotografia, quando ela parece sair da arte contemporânea? Evidentemente as aventuras singulares dos artistas continuarão, mas que fenômeno marcante irá se destacar? Nós todos o ignoramos, a menos que déssemos uma de messias, mas o que é certo, no entanto, é que o momento de uma história comum à arte e à fotografia mudou radicalmente a questão do estatuto das imagens fotográficas.

\section{Referências bibliográficas}

ARENDT, Hannah. "La crise de la culture, sa portée sociale et politique", La crise de la culture. Traduction Barbara Cassin. Paris, Gallimard, Collection folio essais, 1961, p. 253-288.

BRUNET, François. La naissance de l'idée de photographie, Presse Universitaires de France, 2011.

KATZ, Leslie, "Interview with Walker Evans", Art in America, March-April 1971.

POIVERT, Michel. La photographie contemporaine. Paris, Flammarion, 2010.

ROBERTS, John. The Impossible document, Photography and Conceptual art in Britain 1966-1976, Camera Work, Londres, 1997. 